\title{
AORTIC VALVE REPLACEMENT: IS VALVE SIZE IMPORTANT?
}

Benjamin Medalion, MD ${ }^{\mathrm{a}}$ Eugene H. Blackstone, MD ${ }^{\mathrm{a}, \mathrm{b}}$ Bruce W. Lytle, MD Jennifer White, $\mathrm{MS}^{\mathrm{b}}$ John H. Arnold, MD Delos M. Cosgrove, MD
Objective: We sought to determine whether aortic prosthesis size adversely influences survival after aortic valve replacement.

Methods: A total of 892 adults receiving a mechanical $(n=346)$, pericardial $(\mathrm{n}=463)$, or allograft $(\mathrm{n}=83)$ valve for aortic stenosis were observed for up to 20 years (mean, $5.0 \pm 3.9$ years) after primary isolated aortic valve replacement. We used multivariable propensity scores to adjust for valve selection factors, multivariable hazard function analyses to identify risk factors for all-cause mortality, and bootstrap resampling to quantify the reliability of the results.

Results: Twenty-five percent of patients had indexed internal orifice areas of less than $1.5 \mathrm{~cm}^{2} / \mathrm{m}^{2}$ and more than $2 \mathrm{SDs}$ (Z-value) below predicted normal aortic valve size. Mechanical valve orifices were smaller $\left(1.3 \pm 0.29 \mathrm{~cm}^{2} / \mathrm{m}^{2}\right.$, $\mathrm{Z}=-2.2 \pm 1.16)$ than pericardial $\left(1.9 \pm 0.36 \mathrm{~cm}^{2} / \mathrm{m}^{2}, \mathrm{Z}=-0.40 \pm 1.01\right)$ or allograft valves $(2.1 \pm 0.50, \mathrm{Z}=0.24 \pm 1.17)$. The overall survival was $98 \%$, $96 \%, 86 \%, 69 \%$, and $49 \%$ at 30 days and $1,5,10$, and 15 years postoperatively. Univariably, survival was weakly and inversely related to manufacturer valve size $(P=.16)$ and internal orifice diameter $(P=.2)$ but completely unrelated to indexed valve area $(P=.6)$ or $\mathrm{Z}$-value $(P=.8)$. These, and univariable differences among valve types $(P=.004)$, were accounted for by different prevalences in patient risk factors and not by valve size or type per se. Bootstrap resampling indicated that these findings had a less than $15 \%$ chance of being incorrect.

Conclusions: Survival after aortic valve replacement is strongly related to patient risk factors but appears not to be adversely affected by moderate patient-prosthesis mismatch (down to about 4 SDs below normal). Aortic root enlargement to accommodate a large prosthesis may be required in few situations. (J Thorac Cardiovasc Surg 2000;119:963-74)
$\mathrm{T}_{\mathrm{p}}^{\mathrm{n}}$ here is uncertainty as to the optimum management of patients with a small aortic anulus. ${ }^{1}$ Small aortic prostheses may leave higher residual pressure gradients across the valve and are associated with less rapid and less complete regression of left ventricular hypertrophy. ${ }^{2,3}$ Thus a

From the Department of Thoracic and Cardiovascular Surgery and the Department of Biostatistics and Epidemiology, ${ }^{\mathrm{b}}$ The Cleveland Clinic Foundation, Cleveland, Ohio.

Read at the Seventy-ninth Annual Meeting of The American Association for Thoracic Surgery, New Orleans, La, April 18-21, 1999

Received for publication April 22, 1999; revisions requested Aug 23, 1999; revisions received Oct 14, 1999; accepted for publication Oct 18,1999

Address for reprints: Bruce W. Lytle, MD, Department of Thoracic and Cardiovascular Surgery, 9500 Euclid Ave, Desk F25, Cleveland, OH 44195 (E-mail: lytleb@ccf.org).

Copyright $\odot 2000$ by The American Association for Thoracic Surgery $0022-5223 / 2000 \$ 12.00+0 \quad \mathbf{1 2 / 6 / 1 0 3 7 2 7}$

doi:10.1067/mtc.2000.103727 large-sized prosthesis seems preferable. On the other hand, aortic root enlargement may complicate an operation for aortic valve replacement., ${ }^{1,-11}$ Furthermore, patients with small annular size may be small individuals, and the small valve size may be matched to their cardiac output needs. In addition to this uncertainty with respect to the small aortic root, there is also controversy about valve size and efficiency in general. Both the use of stentless aortic valve prostheses and the use of aortic root-enlarging procedures are strategies based in large part on the thesis that hemodynamic performance, and thus valve size, favorably influence late outcome. ${ }^{12}$ The purpose of this study was to ascertain the relation of prosthesis size to survival after aortic valve replacement.

\section{Materials and methods}

Patients. To obtain a relatively pure relation of prosthesis size to survival, we identified adult patients ( $\geq 18$ years of age) operated on at The Cleveland Clinic Foundation from 1978 
Table I. Relation between labeled prosthesis size and internal orifice diameter

\begin{tabular}{|c|c|c|c|}
\hline \multirow[b]{2}{*}{ Labeled size } & \multicolumn{2}{|c|}{ Diameter $(\mathrm{mm})$} & \multirow[b]{2}{*}{$N$} \\
\hline & $\begin{array}{l}\text { Internal } \\
\text { orifice }\end{array}$ & $\begin{array}{l}\text { External } \\
\text { sewing ring }\end{array}$ & \\
\hline $\begin{array}{l}\text { St Jude Medical, } \\
\text { standard (A-101) }\end{array}$ & & & 346 \\
\hline 19 & 14.7 & 19 & 57 \\
\hline 21 & 16.7 & 21 & 91 \\
\hline 23 & 18.5 & 23 & 117 \\
\hline 25 & 20.4 & 25 & 50 \\
\hline 27 & 22.3 & 27 & 22 \\
\hline 29 & 24.1 & 29 & 9 \\
\hline $\begin{array}{l}\text { Carpentier-Edwards Perimoun } \\
\text { RSR Pericardial (2800) }\end{array}$ & & & 463 \\
\hline 19 & 18 & 26 & 110 \\
\hline 21 & 20 & 28 & 137 \\
\hline 23 & 22 & 31 & 126 \\
\hline 25 & 24 & 32 & 73 \\
\hline 27 & 26 & 35 & 16 \\
\hline 29 & 28 & 37 & 1 \\
\hline Allograft & & & 83 \\
\hline 17 & 17 & - & 1 \\
\hline 18 & 18 & - & 1 \\
\hline 19 & 19 & - & 3 \\
\hline 20 & 20 & - & 5 \\
\hline 21 & 21 & - & 9 \\
\hline 22 & 22 & - & 23 \\
\hline 23 & 23 & - & 18 \\
\hline 24 & 24 & - & 9 \\
\hline 25 & 25 & - & 4 \\
\hline 26 & 26 & - & 5 \\
\hline 27 & 27 & - & 3 \\
\hline 29 & 29 & - & 1 \\
\hline 33 & 33 & - & 1 \\
\hline Total & & & 892 \\
\hline
\end{tabular}

through 1996 with (1) aortic stenosis (with or without regurgitation); (2) no concomitant procedures, such as coronary artery bypass grafting; (3) no previous cardiac surgery; and (4) one of three different categories of devices with different expected orifice sizes with respect to the anulus. Through the Cardiovascular Information Registry (CVIR), a prospective ongoing registry of surgical and cardiologic procedures, we identified 892 patients with aortic stenosis who had undergone primary isolated aortic valve replacement with either (1) a mechanical prosthesis (St Jude Medical, standard, A101, n = 346; St Jude Medical, Inc, St Paul, Minn), (2) a bovine pericardial valve (Carpentier-Edwards Perimount RSR 2800, $\mathrm{n}=463$; Baxter Healthcare Corp, Edwards Division, Santa Ana, Calif), or (3) a cryopreserved allograft (CryoLife, $n=$ 83; CryoLife, Inc, Kennesaw, Ga).

Preoperative symptoms were classified according to New York Heart Association (NYHA) criteria. Patients underwent preoperative left heart catheterization with coronary arteriography, echocardiography, or both. Left ventricular function was evaluated by echocardiography and by the left ventriculogram, when available, and grouped by function as being normal or as having mild, moderate, or severe impairment. Other variables used in the data analyses were obtained from the concurrently abstracted data in the CVIR (see Appendix I).

Prostheses. Prosthesis selection was according to surgeon preference. The numbers of patients receiving each prosthesis type and size are presented in Table I. The relation of prosthesis size to survival was investigated by using 4 different expressions of prosthesis size. First, the manufacturer's labeled size (see Table I) is commonly used to express prosthesis size. However, this was the external sewing ring size in the mechanical valve, the tissue mounting device (anulus) size in the pericardial valve, and the internal diameter in the allografts. Second, each manufacturer provided us with its official documentation of internal valve orifice diameter (Table I), and we used this measurement as a uniform valve size expression across valve types, as suggested by Christakis and colleagues. ${ }^{13}$ Third, we then calculated the indexed internal valve orifice area as the internal area divided by the body surface area of the patient (in $\mathrm{cm}^{2} / \mathrm{m}^{2}$ ). Finally, the final expression of valve size was the standardized internal valve orifice size or Z-value based on body surface area. The Zvalue is the number of SDs the internal orifice size differs from the predicted mean normal native aortic valve size on the basis of the patient's body surface area (Appendix II). ${ }^{14,15}$

The relation of labeled prosthesis size to patient characteristics was investigated by using multiple linear regression with the demographic and clinical variables listed in Appendix I.

Follow-up and end point. Patients were followed within the CVIR at 2-year intervals. Attempts were made to contact any patient for whom follow-up was not current by mail, telephone calls, or both during the summer of 1998. In all, patients were followed for 4415 patient-years. Mean followup among survivors was $5.0 \pm 3.9$ years; $25 \%$ were followed up for 2 years or less, and $25 \%$ were followed up for 6 years or more, with a maximum of 20 years. Twenty-seven patients had incomplete follow-up of less than 6 months' duration (3\%).

The end point for this study was death from any cause, with time zero being the time of operation.

\section{Data analysis}

Adjustment for patient selection. Although the availability of several different categories of valves (mechanical, pericardial, and allografts) provided an opportunity to investigate a wide range of internal valve orifice sizes, the kind of patients receiving each were not the same (Table II), and the time frame for the use of each prosthesis was not uniform (Appendix Fig 1). To take into account these selection factors, the probability that a patient would receive one of the 3 types of valve was determined by logistic regression of each pair of valves. For this so-called propensity score (the propensity to receive one or another valve), demographic, symptom and cardiac comorbidity, and noncardiac comorbidity factors shown in Table II were entered into each analysis irrespective of $P$ values. ${ }^{16-18}$ Because the models incorporated identical variables, the sum of the conditional probabilities predicted for receiving each valve add to $100 \%$. The pair- 
Table II. Patient characteristics according to type of valve received

\begin{tabular}{|c|c|c|c|c|c|c|c|}
\hline \multirow[b]{2}{*}{ Variable } & \multicolumn{2}{|c|}{ Pericardial } & \multicolumn{2}{|c|}{ Mechanical } & \multicolumn{2}{|c|}{ Allograft } & \multirow[b]{2}{*}{$\mathrm{P}$ value } \\
\hline & No. & $\%$ of 463 & No. & $\%$ of 346 & No. & $\%$ of 83 & \\
\hline \multicolumn{8}{|l|}{ Demography } \\
\hline Women & 226 & 49 & 159 & 46 & 26 & 31 & .01 \\
\hline Age (y) & \multicolumn{2}{|c|}{$71 \pm 9.1$} & \multicolumn{2}{|c|}{$60 \pm 11.1$} & \multicolumn{2}{|c|}{$48 \pm 9.2$} & $<.0001$ \\
\hline Body surface area $\left(\mathrm{m}^{2}\right)$ & \multicolumn{2}{|c|}{$1.9 \pm 0.25$} & \multicolumn{2}{|c|}{$1.9 \pm 0.25$} & \multicolumn{2}{|c|}{$2.0 \pm 0.22$} & .0002 \\
\hline \multicolumn{8}{|l|}{$\begin{array}{l}\text { Symptoms and cardiac } \\
\text { comorbidity }\end{array}$} \\
\hline NYHA class & & & & & & & .14 \\
\hline I & 82 & 18 & 65 & 19 & 24 & 29 & \\
\hline II & 277 & 60 & 201 & 58 & 47 & 57 & \\
\hline III & 75 & 16 & 62 & 18 & 10 & 12 & \\
\hline IV & 29 & 6 & 18 & 5 & 1 & 1 & \\
\hline Not classified & - & - & - & - & - & 1 & \\
\hline \multicolumn{7}{|l|}{ Left ventricular dysfunction } & .3 \\
\hline Normal & 336 & 73 & 257 & 75 & 62 & 82 & \\
\hline Mild & 50 & 11 & 38 & 11 & 5 & 7 & \\
\hline Moderate & 51 & 11 & 30 & 9 & 9 & 11 & \\
\hline Severe & 23 & 5 & 16 & 5 & 0 & 0 & \\
\hline Not classified & 3 & - & 5 & - & 7 & - & \\
\hline \multicolumn{7}{|l|}{$\begin{array}{c}\text { Known (and unbypassed) } \\
\text { coronary artery disease }\end{array}$} & .009 \\
\hline None & 396 & 86 & 315 & 92 & 71 & 99 & \\
\hline One-system disease & 47 & 10 & 22 & 6 & 1 & 1 & \\
\hline Two-system disease & 16 & 3 & 4 & 1 & 0 & 0 & \\
\hline Three-system disease & 1 & 0.2 & 0 & 0 & 0 & 0 & \\
\hline Not classified & 3 & - & 5 & - & 6 & - & \\
\hline $\begin{array}{l}\text { Family history of } \\
\text { coronary artery disease }\end{array}$ & $72 / 249^{*}$ & 29 & $85 / 205$ & 41 & $10 / 51$ & 20 & .002 \\
\hline Endocarditis & 7 & 2 & 13 & 4 & 1 & 1 & .09 \\
\hline \multicolumn{8}{|l|}{ Noncardiac comorbidity } \\
\hline Hypertension & $247 / 440$ & 56 & $132 / 346$ & 44 & $23 / 78$ & 29 & .001 \\
\hline Peripheral vascular disease & 80 & 17 & 38 & 11 & 1 & 1 & .001 \\
\hline Diabetes & $63 / 415$ & 15 & $18 / 309$ & 6 & $7 / 75$ & 9 & .001 \\
\hline Chronic lung disease & 64 & 14 & 23 & 7 & 7 & 8 & .004 \\
\hline Renal disease & 20 & 4 & 4 & 1 & 1 & 1 & .02 \\
\hline
\end{tabular}

Means are presented with 1 SD. $P$ values are based on $\chi^{2}$ statistics for categoric variables and the Kruskal-Wallis nonparametric test for continuous variables. "In some instances, when information was unavailable, the data are presented as n/number known.

wise propensity scores in the format of logit units were incorporated into multivariable analyses of death as a way to adjust for selection factors.

Effectiveness of risk adjustment. In multivariable analyses of survival, we did not find the propensity scores to be importantly or significantly related to survival. To test whether the factors related to survival thus already adjusted adequately for differences, we generated a separate predicted survival curve for each patient on the basis of his or her valves for risk factors. These were then superimposed on stratified univariable life table estimates to ascertain the effectiveness of conventional risk adjustment. ${ }^{19}$

Analysis of survival. Nonparametric estimates of survival were obtained by the method of Kaplan and Meier. ${ }^{20}$ A parametric method was used to resolve the number of phases of instantaneous risk of death (hazard function) and to estimate its shaping parameters. ${ }^{21}$
Exploratory analyses of the variables in Appendix I included correlation analysis, stratified life table analyses, and decile risk analysis of ordinal and continuous variables to determine the possible transformations of scale needed to properly calibrate the variables to survival.

The risk of small valve size might be prominent early after the operation or it may be a long-term risk. For this reason, we used a method that simultaneously but specifically interrogated the early, constant, and late hazard phases after the operation. ${ }^{21}$ The analyses used a directed technique of entry of variables into the multivariable model. ${ }^{22}$ The $P$ value criterion for retention of variables in the final model was .05 .

Reliability of the analysis. Because we were unable to identify an influence of prosthesis size on survival, we ascertained the reliability of this finding by using bootstrap resampling. ${ }^{23}$ Patients were drawn at random from the 892 study members with replacement. This was repeated to construct a new data 

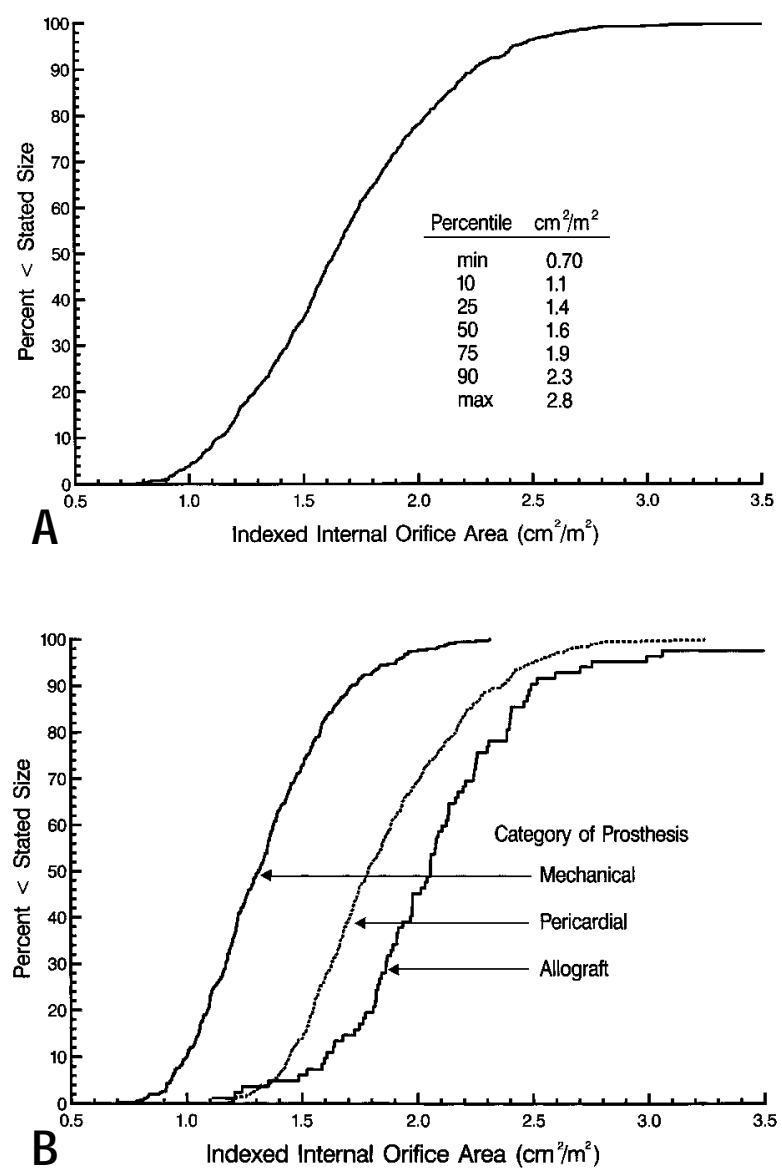

Fig 1. Cumulative distribution of prosthesis internal orifice area indexed to body surface area. For orientation, the valve size value along the horizontal axis corresponding to 50 along the vertical axis is the median size; those at $25 \%$ and $75 \%$ are the quartile values. A value of effective orifice size, which will be smaller than these full-orifice sizes, below 0.85 $\mathrm{cm}^{2} / \mathrm{m}^{2}$ is considered to constitute patient-prosthesis mismatch. A, Overall distribution; $\mathbf{B}$, distribution stratified by type of aortic valve prosthesis.

set of 892 observations, which could contain one or more duplicates of patients. This random sampling process was repeated 1000 times to create 1000 differently constituted data sets. We then inquired how often smaller valve size would be selected as a risk factor at a $P$ value of less than .05 in each hazard phase adjusted for the other factors found by parsimonious modeling and the propensity scores. ${ }^{24}$

The bootstrap variable selection process was carried out for indexed internal valve orifice area overall and repeated with the indexed areas for the individual valve types (as interaction terms). This entire process was repeated by using the standardized internal orifice size (Z-value). Thus 4000 separate data sets were actually used in these 4 investigations. Because of the small number of events in the early hazard phase, this
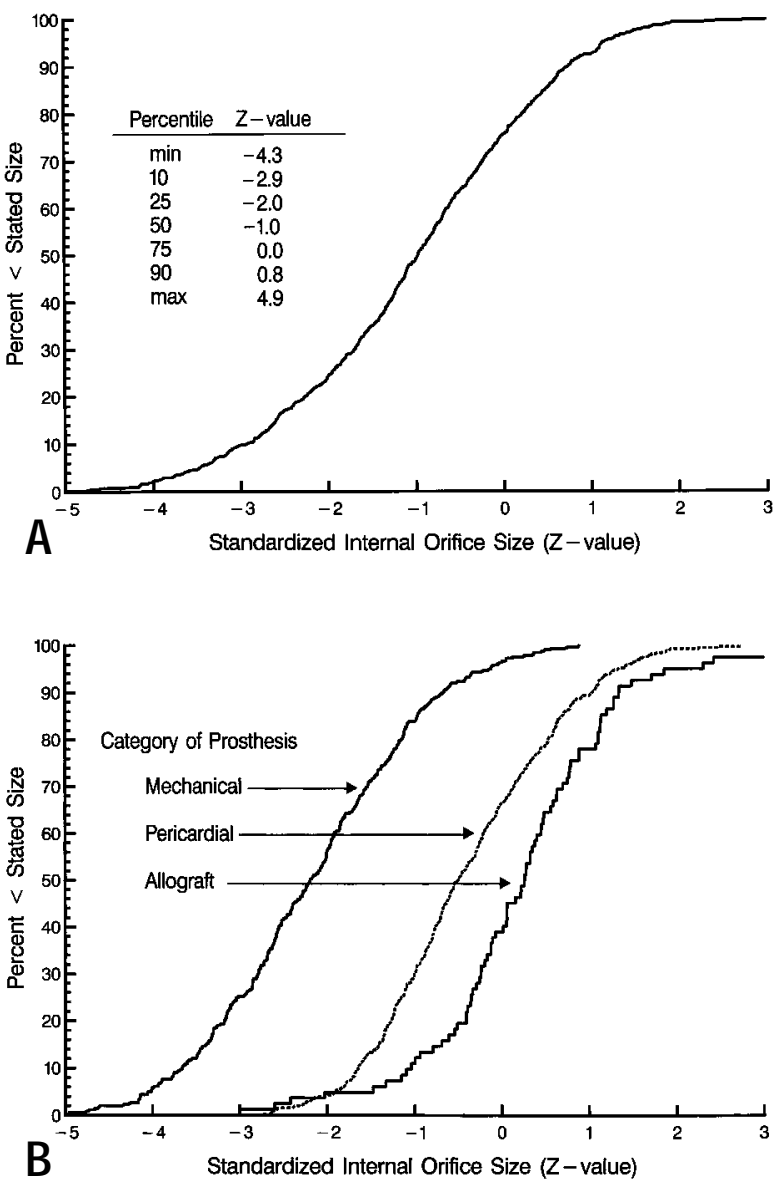

Fig 2. Cumulative distribution of prosthesis internal orifice size standardized to body surface area according to the Zvalue. The Z-value represents the number of SDs the internal orifice size departs from the mean normal native aortic valve for a given body surface area. Normal native valve sizes are generally considered to be those constrained within the $95 \%$ confidence limits of normal values, corresponding to Z-values of -2 and +2 . A, Overall distribution; $\mathbf{B}$, distribution stratified by type of aortic valve prosthesis.

investigation was only conducted for the constant and late hazard phases.

\section{Results}

Prosthesis size. The frequency of use of prostheses of varying labeled and internal orifice size are shown in Table I. The complete spectrum of internal orifice area indexed to body surface area and its relation to the type of valve is shown in Fig 1 . Only 7 patients received valves with indexed internal orifice areas below 0.85 $\mathrm{cm}^{2} / \mathrm{m}^{2}$. Mechanical prostheses had the smallest orifice size $\left(1.3 \pm 0.29 \mathrm{~cm}^{2} / \mathrm{m}^{2}, \mathrm{Z}=-2.2 \pm 1.16\right)$, and allografts had the largest in relation to body size $(2.1 \pm 0.50$ 
Table III. Comparison of characteristics of patients receiving small (19 $\mathrm{mm}$ or less labeled size) and larger (greater than $19 \mathrm{~mm}$ ) prostheses

\begin{tabular}{|c|c|c|c|c|c|}
\hline \multirow[b]{2}{*}{ Variable } & \multicolumn{2}{|c|}{$\leq 19 \mathrm{~mm}$} & \multicolumn{2}{|c|}{$>19 \mathrm{~mm}$} & \multirow[b]{2}{*}{$\mathrm{P}$ value } \\
\hline & No. & $\%$ of 172 & No. & $\%$ of 720 & \\
\hline Women & 161 & 94 & 250 & 35 & $<.001$ \\
\hline Age (y) & \multirow{2}{*}{\multicolumn{2}{|c|}{$\begin{array}{r}69 \pm 11.5 \\
1.7 \pm 0.21\end{array}$}} & \multicolumn{2}{|c|}{$63 \pm 12.3$} & $<.0001$ \\
\hline Body surface area $\left(\mathrm{m}^{2}\right)$ & & & \multicolumn{2}{|c|}{$2.0 \pm 0.23$} & $<.0001$ \\
\hline NYHA class III-IV & 37 & 22 & $158 / 719^{*}$ & 22 & .9 \\
\hline $\begin{array}{l}\text { Moderate or severe left ventricular } \\
\text { dysfunction }\end{array}$ & $14 / 171$ & 8 & $115 / 706$ & 16 & .007 \\
\hline Diabetes & $18 / 155$ & 12 & $70 / 644$ & 11 & .8 \\
\hline Peripheral vascular disease & 31 & 18 & 88 & 12 & .04 \\
\hline Hypertension & $95 / 164$ & 58 & $307 / 651$ & 47 & .01 \\
\hline Type of valve & & & & & $<.001$ \\
\hline Mechanical & 57 & 33 & 289 & 40 & .09 \\
\hline Pericardial & 110 & 64 & 353 & 49 & $<.001$ \\
\hline Allograft & 5 & 3 & 78 & 11 & $<.001$ \\
\hline
\end{tabular}

Means are presented with 1 SD. $P$ values are based on $\chi^{2}$ statistics for categoric variables and the Kruskal-Wallis nonparametric test for continuous variables.

*In some instances, when information was unavailable, the data are presented as n/number known.

$\left.\mathrm{cm}^{2} / \mathrm{m}^{2}, \mathrm{Z}=0.24 \pm 1.17\right)$, with pericardial valves being intermediate between the $2\left(1.9 \pm 0.36 \mathrm{~cm}^{2} / \mathrm{m}^{2}, \mathrm{Z}=\right.$ $-0.40 \pm 1.01)$. A quarter of the patients, mostly those receiving a mechanical prosthesis, had internal valve orifice sizes more than 2 SDs below normal native aortic anulus size (Fig 2).

Patients receiving small-sized prostheses differed in many respects from those receiving larger manufacturer's label-sized valves (Table III). For example, patients receiving size 19 or smaller prostheses were more likely to be women, smaller in size, more likely to have hypertension and peripheral vascular disease, more likely to receive a pericardial valve, and less likely to have left ventricular dysfunction.

By using multiple regression, the factors associated with manufacturer-labeled valve size were female sex $(-2.2 \pm 0.141 \mathrm{~mm}$ smaller, $P<.0001)$, body size $\left(1.91 \pm 0.29 \mathrm{~mm} / \mathrm{m}^{2}\right.$ increase, $\left.P<.0001\right)$, left ventricular dysfunction $(0.197 \pm 0.072 \mathrm{~mm}$ per grade increase [0-3], $P=.006$ ), and age (younger: $-1.06 \pm$ $0.23 \cdot[\text { age } / 50]^{2}, P<.0001$; older: $-1.38 \pm 0.67 \cdot[50 /$ age], $P=.04)$.

Survival. The overall survival was $98 \%, 96 \%, 86 \%$, $69 \%$, and $49 \%$ at 30 days and $1,5,10,15$ years, respectively (Fig 3). There were only 13 hospital deaths $(1.5 \%)$, precluding any meaningful examination of early risk factors. Thus we focused on deaths across time from the time of operation. The instantaneous risk of death (hazard function) was highest immediately after valve replacement but fell rapidly to its lowest level and gradually rose after about 3 months. This pattern of risk and the methods of analysis used allowed us to focus on the influence of valve size at various time intervals after operation.

Risk factors for death included older age, smaller body size, endocarditis, family history of ischemic heart disease, chronic lung disease, and chronic renal disease (Table IV). Only small body size was identified in the early hazard phase, and the others were distributed between constant and late hazard phases. No valve type or expression of valve size was identified as a risk factor.

Survival by valve type and size. By using univariable stratified life table analysis, differences in survival among patients with different valve types were apparent $(P=.004)$, as shown in Fig 4. However, these differences were accounted for by the patient's risk factors, as demonstrated by the smooth curves in the figure. These curves represent the risk-adjusted, individual patient predictions on the basis of the multivariable analysis and averaged within valve types.

When the patients are stratified by labeled valve size, smaller valves were associated with somewhat greater risk $(P=.16$; Fig $5, A)$, but this difference was accounted for well by the differences in patient characteristics that influenced survival (smooth curves in the figure). Stratification by indexed internal orifice area rather than labeled size inverts this relation (Fig 5, B). Although not a statistically significant association $(P=$ .6), the small differences were well accounted for by differences in prevalence of risk factors. These same findings were true of internal orifice size standardized to predicted normal native aortic valve size $(P=.8$; Fig $5, C$ ). Thus all differences related to prosthesis type and 

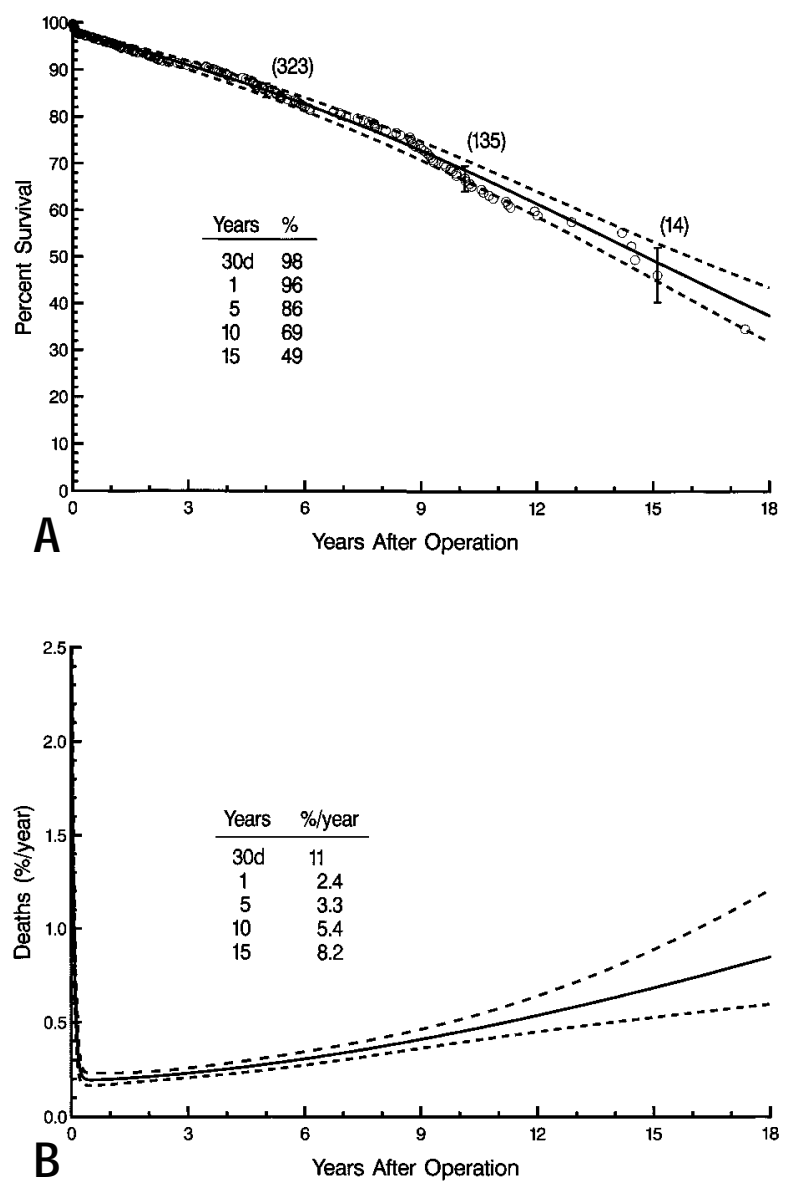

Fig 3. Overall survival. A, Nonparametric (Kaplan-Meier) and parametric estimates of overall survival. The circles are the nonparametric estimates. The vertical bars are confidence limits, equivalent to $1 \mathrm{SE}$. The numbers of patients remaining at 2-year intervals are shown in parentheses. The smooth line is the parametric survival estimate, and the dashed lines are its confidence limits equivalent to $1 \mathrm{SE}$. B, Instantaneous risk of death (hazard function).

various expressions of valve size were well accounted for by differences in prevalence of risk factors.

Table $\mathrm{V}$, in which valve type and indexed internal valve area were forced into the multivariable model, demonstrates little association of these factors with survival. The same was true of the Z-value (Table VI).

The reliability of our inference that smaller valve size is not associated adversely with survival was assessed by bootstrap resampling (Table VII). This analysis demonstrates that in studies of this size, less than $15 \%$ will demonstrate an effect of small valve size on survival with a $P$ value of less than .05 . In the phase important in the long term, this was reduced to less than a $4 \%$ chance.

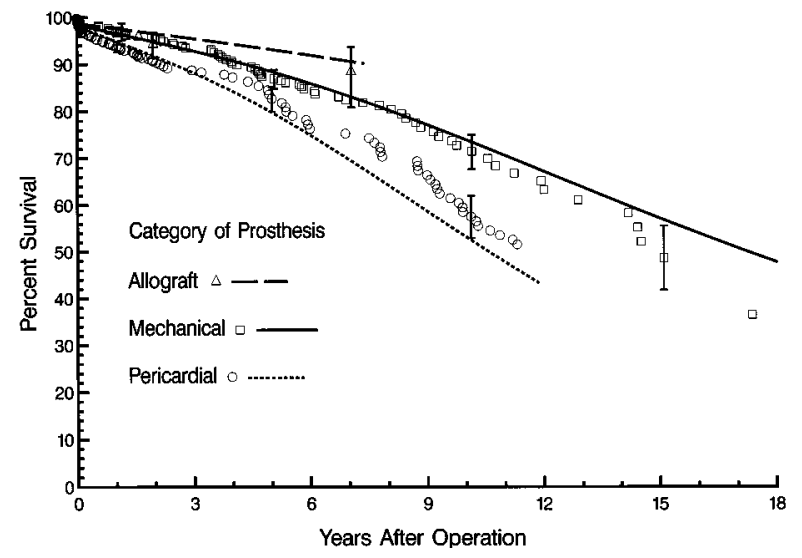

Fig 4. Survival with patients stratified by type of prosthesis. The smooth curves are derived from the risk factor analysis (Table IV) that does not include valve type, demonstrating that the differences are accounted for by differing prevalences of risk factors (see the "Methods" section).

\section{Discussion}

Study strengths. In this study we have examined the question of the influence on survival of aortic valve size in a relatively pure group of patients that emphasizes small valve size (aortic stenosis). It is a relatively large study, and the variables examined were collected concurrently with the surgery into a registry. Follow-up has been systematic. We have used all-cause death as our end point because it is unequivocal and devoid of subjective interpretation.

We have used modern sophisticated methods to interpret the data in the face of nonuniform prosthesis selection and the nonrandomized nature of the study. We have then tested the reliability of our inferences by using computer-intensive sampling methodology.

Study limitations. The patients represent a single institution's experience and therefore may not be representative of other venues. This is not a randomized study and is retrospective, leaving the possibility that selection bias might cause differences in patient groups that might influence survival but are not accounted for, even with the extensive multivariable analyses conducted. Furthermore, this study does not examine all outcomes but only survival. For patients undergoing aortic valve replacement, meaningful survival data can only be obtained from studies with large patient numbers. It is quite difficult to examine indices of left ventricular mass regression over time and subtleties of late symptom status for this large number of patients followed for these postoperative intervals.

Importantly, the study is limited to patients with at most moderate patient-prosthesis mismatch ${ }^{25}$ because 
Table IV. Risk factors for death after aortic valve replacement identified by multivariable analysis

\begin{tabular}{|c|c|c|c|c|c|c|}
\hline \multirow[b]{3}{*}{ Incremental risk factors for death } & \multicolumn{6}{|c|}{ Hazard phase } \\
\hline & \multicolumn{2}{|l|}{ Early } & \multicolumn{2}{|c|}{ Constant } & \multicolumn{2}{|c|}{ Late } \\
\hline & Coefficient $\pm S D$ & $\mathrm{P}$ value & Coefficient $\pm S D$ & $\mathrm{P}$ value & Coefficient $\pm S D$ & $\mathrm{P}$ value \\
\hline \multicolumn{7}{|l|}{ Demography } \\
\hline Older age & - & - & $0.036 \pm 0.0119$ & .002 & $0.13 \pm 0.027$ & $<.0001$ \\
\hline Body surface area & $-3.3 \pm 1.42$ & .02 & - & - & - & - \\
\hline \multicolumn{7}{|l|}{ Cardiac comorbidity } \\
\hline Family history of ischemic heart disease & - & - & - & - & $0.85 \pm 0.36$ & .02 \\
\hline Preoperative endocarditis & - & - & $1.61 \pm 0.45$ & .0003 & - & - \\
\hline \multicolumn{7}{|l|}{ Noncardiac comorbidity } \\
\hline History of smoking & - & - & - & - & $0.93 \pm 0.36$ & .01 \\
\hline Chronic obstructive pulmonary disease & - & - & $0.86 \pm 0.34$ & .01 & - & - \\
\hline Chronic renal disease & - & - & $2.4 \pm 0.4$ & $<.0001$ & - & - \\
\hline
\end{tabular}

no deliberate attempt was made to use an undersized prosthesis. Nevertheless, some $25 \%$ of patients had moderate mismatch.

The patients were not randomized with respect to either valve type or valve size. Indeed, deliberate selection of specific valve types for different patients is generally accepted in this mature era of valve replacement. We used 3 valve types to examine a wide spectrum of internal orifice sizes, even though this introduced a possible confounding variable. We addressed this by use of propensity scores to account for this selection. Of course, we were unable to take into account unrecorded selection factors. The fact that in no instances were the propensity scores associated with survival indicates that the factors in the multivariable analysis adjusted well for patient heterogeneity with respect to valve type selection.

We have used actual (in vitro) valve dimensions, even when normalized and standardized to body surface area, rather than effective valve orifice area. The effective valve orifice area is a dynamic, and not static, measurement that varies with temporal loading conditions and flow. Thus it is a poor variable for the kinds of comparison done in this study. Commonly, the labeled valve size has been used in discussions of small prostheses. This size clearly refers to different measurement points for each valve type. We have therefore used a uniform measurement for comparisons: the internal diameter of the prosthesis.

Finally, follow-up, although extending up to 20 years, averaged only 5 years. Thus the inferences apply mainly to intermediate-term survival.

Valve size. Both the use of stentless aortic valve prostheses and the use of aortic root-enlarging procedures are strategies based in large part on the thesis that favorable hemodynamics from a large and efficient prosthetic orifice size will improve late outcomes after aortic valve replacement.

In part, this logic is based on the exponential increase in the transprosthetic pressure gradient as indexed effective orifice size decreases, particularly below about 1 $\mathrm{cm}^{2} / \mathrm{m}^{2} \cdot{ }^{26,27}$ The magnitude of this gradient in a pulse duplicator system may be $20 \mathrm{~mm} \mathrm{Hg}$ at a cardiac index of $4.5 \mathrm{~L} \cdot \mathrm{min}^{-1} \cdot \mathrm{m}^{-2}$ at an indexed effective orifice area of $1.0 \mathrm{~cm}^{2} / \mathrm{m}^{2}$. Because prostheses are not perfectly efficient in vivo, the effective orifice area is generally less than the calculated internal orifice area used in our study. Any component of left ventricular outflow obstruction must be added to the transprosthetic pressure gradient. ${ }^{27}$

In part, this logic is based on the more rapid and complete regression of left ventricular hypertrophy in the first few years after aortic valve replacement, as assessed by echocardiography. ${ }^{2,3,28}$ In part, it is also because others have found a relation between manufacturer-labeled prosthesis size and overall time-related survival. ${ }^{29}$ The magnitude of this relation appeared to be modest and in part related to differences in mortality after the operations.

In the present study the consumption of space by sewing rings and stents is reflected in the indexed orifice area and standardized orifice size. However, we were unable to demonstrate an adverse relation between smaller valve size by any of the 4 different expressions and intermediate-term survival. This is a broad statement in the context of many older patients requiring aortic valve replacement for aortic stenosis; there may be individual patients for whom prosthesis size may be important.

This leaves unexplained the differences in intermediate-term survival in the case-matched study of the 

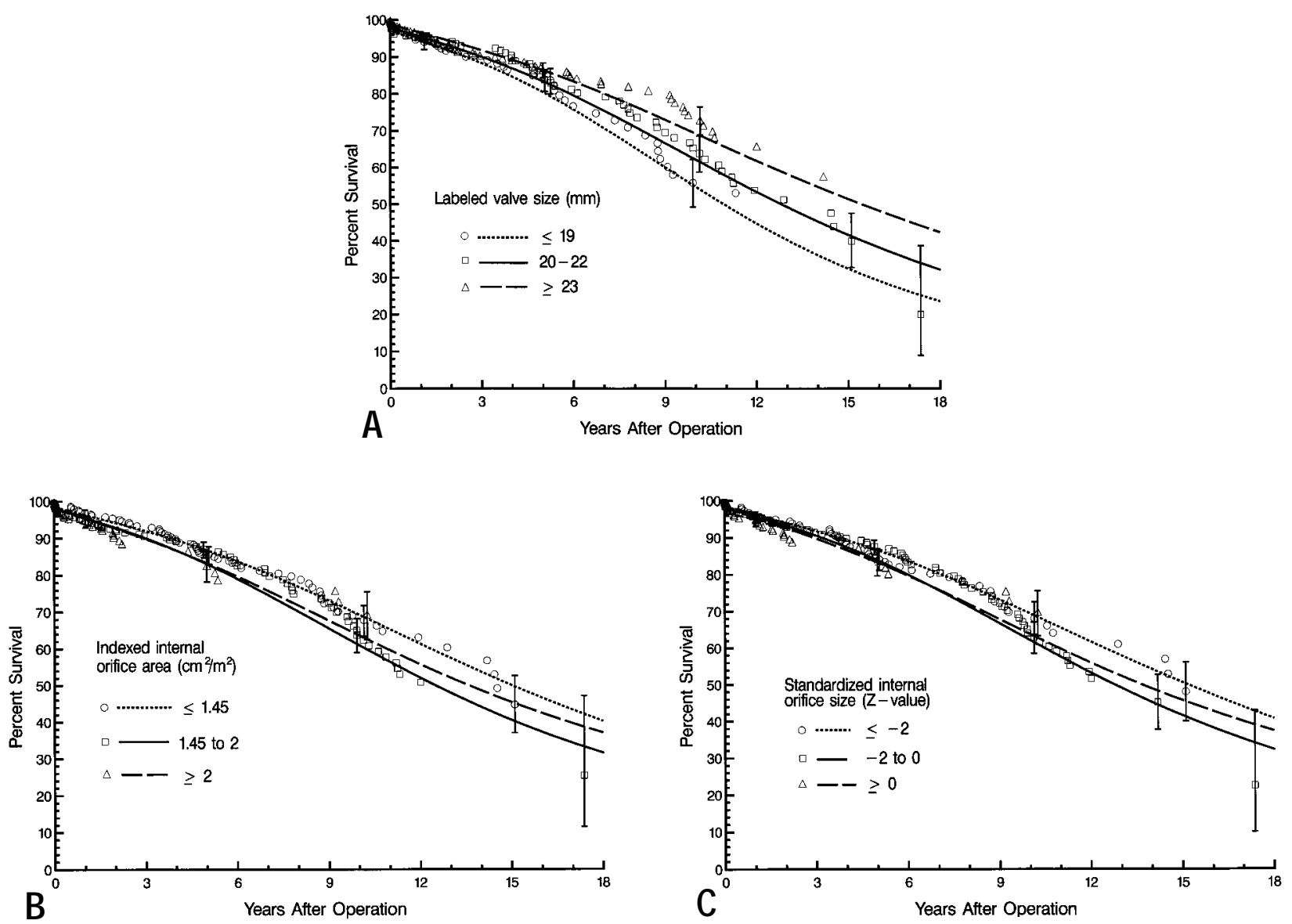

Fig 5. Survival with patients stratified by various expressions of prosthesis size. The smooth curves are derived from the multivariable analysis (Table IV), as described in Fig 4 and the "Methods" section. A, Stratification by labeled valve size (in $\mathrm{mL}$ ); $\mathbf{B}$, stratification by indexed internal orifice area (in $\mathrm{cm}^{2} / \mathrm{m}^{2}$ ); and $\mathbf{C}$, stratification by standardized internal orifice size (Z-value).

Table V. Risk factors for death after aortic valve replacement with prosthesis type and size (expressed as valve area per square meter) forced into the model

\begin{tabular}{|c|c|c|c|c|c|c|}
\hline \multirow[b]{3}{*}{ Incremental risk factors for death } & \multicolumn{6}{|c|}{ Hazard phase } \\
\hline & \multicolumn{2}{|l|}{ Early } & \multicolumn{2}{|c|}{ Constant } & \multicolumn{2}{|c|}{ Late } \\
\hline & Coefficient $\pm S D$ & $\mathrm{P}$ value & Coefficient $\pm S D$ & $\mathrm{P}$ value & Coefficient $\pm S D$ & $\mathrm{P}$ value \\
\hline \multicolumn{7}{|l|}{ Prosthesis } \\
\hline Pericardial & - & - & $-0.32 \pm 1.1$ & .8 & $-0.52 \pm 9.3$ & .9 \\
\hline Mechanical & - & - & $-0.23 \pm 1.1$ & .8 & $-0.55 \pm 6.0$ & .9 \\
\hline Indexed internal orifice area $\left(\mathrm{cm}^{2} / \mathrm{m}^{2}\right)$ & - & - & $-0.26 \pm 0.38$ & .5 & $-0.0024 \pm 0.079$ & .9 \\
\hline \multicolumn{7}{|l|}{ Demography } \\
\hline Older age & - & - & $0.04 \pm 0.014$ & .004 & $0.14 \pm 0.029$ & $<.0001$ \\
\hline Body surface area & $-3.4 \pm 1.4$ & .02 & - & - & - & - \\
\hline \multicolumn{7}{|l|}{ Cardiac comorbidity } \\
\hline Family history of coronary artery disease & - & - & - & - & $0.86 \pm 0.37$ & .02 \\
\hline Preoperative endocarditis & - & - & $1.6 \pm 0.46$ & .0008 & - & - \\
\hline \multicolumn{7}{|l|}{ Noncardiac comorbidity } \\
\hline History of smoking & - & - & - & - & $0.94 \pm 0.43$ & .03 \\
\hline Chronic obstructive pulmonary disease & - & - & $0.87 \pm 0.36$ & .02 & - & - \\
\hline Chronic renal disease & - & - & $2.4 \pm 0.41$ & $<.0001$ & - & - \\
\hline
\end{tabular}


Table VI. Risk factors for death after aortic valve replacement with prosthesis type and size expressed as the number of SDs below the normal native aortic valve size (Z-value) forced into the model

\begin{tabular}{|c|c|c|c|c|c|c|}
\hline \multirow[b]{3}{*}{ Incremental risk factors for death } & \multicolumn{6}{|c|}{ Hazard phase } \\
\hline & \multicolumn{2}{|c|}{ Early } & \multicolumn{2}{|c|}{ Constant } & \multicolumn{2}{|c|}{ Late } \\
\hline & Coefficient $\pm S D$ & $\mathrm{P}$ value & Coefficient $\pm S D$ & $\mathrm{P}$ value & Coefficient $\pm S D$ & $\mathrm{P}$ value \\
\hline \multicolumn{7}{|l|}{ Prosthesis } \\
\hline Pericardial & - & - & $-0.4 \pm 0.6$ & .5 & $0.77 \pm 6.0$ & .9 \\
\hline Mechanical & - & - & $-0.36 \pm 0.62$ & 6 & $0.9 \pm 6.0$ & .9 \\
\hline Standardized internal orifice size (Z-value) & - & - & $-0.1 \pm 0.12$ & .4 & $0.13 \pm 0.027$ & 6 \\
\hline \multicolumn{7}{|l|}{ Demography } \\
\hline Older age & - & - & $0.04 \pm 0.014$ & .003 & $0.14 \pm 0.028$ & $<.0001$ \\
\hline Body surface area & $-3.4 \pm 1.4$ & .02 & - & - & - & - \\
\hline \multicolumn{7}{|l|}{ Cardiac comorbidity } \\
\hline Family history of coronary artery disease & - & - & - & - & $0.89 \pm 0.38$ & .02 \\
\hline Preoperative endocarditis & - & - & $1.6 \pm 0.46$ & .0006 & - & - \\
\hline \multicolumn{7}{|l|}{ Noncardiac comorbidity } \\
\hline History of smoking & - & - & - & - & $0.98 \pm 0.38$ & .009 \\
\hline Chronic obstructive pulmonary disease & - & - & $0.86 \pm 0.35$ & .01 & - & - \\
\hline Chronic renal disease & - & - & $2.4 \pm 0.39$ & $<.0001$ & - & - \\
\hline
\end{tabular}

Table VII. Percentage of 1000 bootstrap resamplings in which smaller valve size appears with $\mathrm{P}$ values of less than .05

\begin{tabular}{lccc}
\hline & \multicolumn{3}{c}{ Hazard phase } \\
\cline { 2 - 4 } $\begin{array}{l}\text { Variables available } \\
\text { for selection }\end{array}$ & $\begin{array}{c}\text { Early } \\
(\%)\end{array}$ & $\begin{array}{c}\text { Constant } \\
(\%)\end{array}$ & $\begin{array}{c}\text { Late } \\
(\%)\end{array}$ \\
\hline Overall assessment & & & \\
$\quad$ Z-value & 1.6 & 13.9 & 2.3 \\
$\quad$ Valve area $\left(\mathrm{cm}^{2} / \mathrm{m}^{2}\right)$ & 0.9 & 11.2 & 1.8 \\
Assessment of valve type & & & \\
$\quad$ and size (Z-value) & - & 8.7 & 2.0 \\
Pericardial & - & 6.5 & 0.5 \\
$\quad$ Mechanical & - & 0.0 & 1.5 \\
$\quad$ Allograft & & & \\
Assessment by valve type & - & 10.7 & 3.3 \\
$\quad$ and size (area, $\left.\mathrm{cm}^{2} / \mathrm{m}^{2}\right)$ & - & 3.7 & 0.7 \\
$\quad$ Pericardial & - & 0.0 & 0.4 \\
$\quad$ Mechanical & & & \\
Allograft & &
\end{tabular}

Toronto stentless prosthesis compared with a stented xenograft. ${ }^{12}$ One can question how well matched that study was (eg, with more aortic regurgitation patients) in the stented group. Aortic enlargement was also used to allow larger stented valve sizes to be used, and this increases the early risk of operation. ${ }^{4}$

This study has focused on survival. Survival is not the only outcome after aortic valve replacement, although it is the most important. There are situations where the use of complex forms of aortic valve replace- ment, such as aortic valve homografts, pulmonary valve autotransplantation, aortic root-enlarging procedures, and, perhaps, stentless heterograft valves, to achieve a more efficient aortic valve substitute are indicated by a desire for a high patient activity level. In those situations we have usually used aortic valve homografts or pulmonary valve autotransplantation. However, on the basis of our study, despite the arguments from logic, survival appears not to be adversely affected by aortic prosthesis size, even down to moderate patient-prosthesis mismatch. Thus except in selected circumstances, doing an operation, such as aortic root enlargement, that increases short-term risk to achieve a better long-term survival is not supported by these data.

We thank Maura Schnauffer and Lucinda Mitchin for the preparation of this manuscript.

\section{REFERENCES}

1. Barratt-Boyes BG, Christie GW. What is the best bioprosthetic operation for the small aortic root? Allograft, autograft, porcine, pericardial? Stented or unstented? J Card Surg 1994;9(Suppl): 158-64.

2. Gonzalez-Juanatey JR, Garcia-Acuna JM, Fernandez MV, et al. Influence of the size of aortic valve prostheses on hemodynamics and change in left ventricular mass: implication for surgical management of aortic stenosis. J Thorac Cardiovasc Surg 1996;112: 273-80.

3. Sim EK, Orszulak TA, Schaff HV, Shub C. Influence of prosthesis size on change in left ventricular mass following aortic valve replacement. Eur J Cardiothorac Surg 1994;8:293-7.

4. Sommers KE, David TE. Aortic valve replacement with patch 
enlargement of the aortic annulus. Ann Thorac Surg 1997;63: 1608-12.

5. Gill CC, King HC, Lytle BW, Cosgrove DM, Golding LA, Loop FD. Early clinical evaluation after aortic valve replacement with the St. Jude Medical valve in patients with a small aortic root. Circulation 1982;66:I147-9.

6. Kratz JM, Sade RM, Crawford FA Jr, Crumbley AJ, Stroud MR. The risk of small St. Jude aortic valve prostheses. Ann Thorac Surg 1994;57:1114-9.

7. Arom KV, Goldenberg IF, Emery RW. Long-term clinical outcome with small size Standard St. Jude Medical valves implanted in the aortic position. J Heart Valve Dis 1994;3:531-6.

8. He GW, Grunkemeier GL, Gately HL, Furnary AP, Starr A. Up to thirty-year survival after aortic valve replacement in the small aortic root. Ann Thorac Surg 1995;59:1056-62.

9. Gonzalez-Juanatey JR, Garcia-Acuna JM, Amaro A, et al. Doppler echocardiographic comparison of small (19mm) bileaflet and pericardial heart valve prostheses in aortic position. Scand J Thorac Cardiovasc Surg 1995;29:29-35.

10. Franzen SF, Huljebrant IE, Konstantinov IE, Nylander E, Olin CL. Aortic valve replacement for aortic stenosis in patients with small aortic root. J Heart Valve Dis 1996;5(Suppl 3):S284-8.

11. Sawant D, Singh AK, Feng WC, Bert AA, Rotenberg F. St. Jude Medical cardiac valves in small aortic roots: follow-up to sixteen years. J Thorac Cardiovasc Surg 1997;113:499-509.

12. David TE, Puschmann R, Ivanov J, et al. Aortic valve replacement with stentless and stented porcine valves: a case-match study. J Thorac Cardiovasc Surg 1998;116:236-41.

13. Christakis GT, Buth KJ, Goldman BS, et al. Inaccurate and misleading valve sizing: a proposed standard for valve size nomenclature. Ann Thorac Surg 1998;66:1198-203.

14. Rinaldi HAS, Lev M. A note on the concept of normality and abnormality in quantitation of pathologic findings in congenital heart disease. Pediatr Clin North Am 1963;10:589-91.

15. Kirklin JW, Barratt-Boyes B. Cardiac surgery. 2nd ed. New York: Churchill Livingstone; 1993. p. 3-60.

16. Rosenbaum P, Rubin DB. The central role of the propensity score in observational studies for causal effects. Biometrika 1983;70: 41-55.

17. Rubin DB. Estimating causal effects from large data sets using propensity scores. Ann Intern Med 1997;127:757-63.

18. Cook EF, Goldman L. Performance of tests of significance based on stratification by a multivariate confounding score or by a propensity score. J Clin Epidemiol 1989;42:312-24.

19. Ferrazzi P, McGiffin DC, Kirklin JW, Blackstone EH, Bourge RC. Have the results of mitral valve replacement improved? J Thorac Cardiovasc Surg 1986;92:186-97.

20. Kaplan EL, Meier P. Nonparametric estimation from incomplete observations. J Am Stat Assn 1958;53:457-81.

21. Blackstone EH, Naftel DC, Turner ME Jr. The decomposition of time-varying hazard into phases, each incorporating a separate stream of concomitant information. J Am Stat Assn 1986;81: 61524.

22. Baskerville JC, Toogood JH. Guided regression modeling for prediction and exploration of structure with many explanatory variables. Technometrics 1982;24:9-17.

23. Efron B, Tibshirani R. Bootstrap methods for standard errors, confidence intervals, and other measures of statistical accuracy. Stat Sci 1986;1:54-77.

24. Altran DG, Andersen PK. Bootstrap investigation of the stability of a Cox regression model. Stat Med 1989;8:771-83.
25. Dumesnil JG, Honos GN, Lemieux M, Beauchemin J. Validation and applications of indexed aortic prosthetic valve areas calculated by Doppler echocardiography. J Am Coll Cardiol 1990;16: 637-43.

26. Dumesnil JG, Yoganathan AP. Valve prosthesis hemodynamics and the problem of high transprosthetic pressure gradients. Eur J Cardiothorac Surg 1992;6(Suppl I):S34-8.

27. Bech-Hanssen O, Wallentin I, Larsson S, Caidahl K. Reference Doppler echocardiographic values for St. Jude Medical, Omnicarbon, and Biocor prosthetic valves in the aortic position. J Am Soc Echocardiogr 1998;11:466-77.

28. Jin XY, Zhang ZM, Gibson DG, Yacoub MH, Pepper JR. Effects of valve substitute on changes in left ventricular function and hypertrophy after aortic valve replacement. Ann Thorac Surg 1996;62:683-90.

29. Morris JJ, Schaff HV, Mullany CJ, et al. Determinants of survival and recovery of left ventricular function after aortic valve replacement. Ann Thorac Surg 1993;56:22-30.

\section{Appendix I: Variables}

The following variables were examined in multivariable analyses:

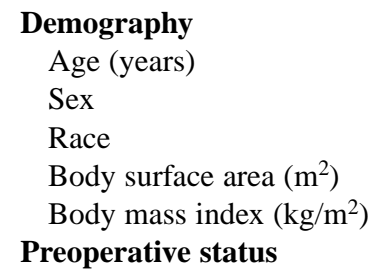

New York Heart Association functional class

Emergency surgery

\section{Left ventricular function}

History of myocardial infarction

Evidence of previous infarction by electrocardiography

Left ventricular dysfunction index (see the "Methods" section)

\section{Other cardiac comorbidity}

Family history of coronary artery disease

Extent of coronary system disease (1-3)

Presence of preoperative atrial fibrillation

Endocarditis

\section{Noncardiac comorbidity}

Smoking

Insulin-treated diabetes

Noninsulin-treated diabetes

Hypertension

Peripheral vascular disease

Chronic obstructive pulmonary disease

Renal disease

Blood urea nitrogen level

\section{Valve surgery}

Prosthesis type

Labeled prosthesis manufacturer size $(\mathrm{mm})$

Prosthesis internal orifice diameter $(\mathrm{mm})$

Indexed internal orifice area $\left(\mathrm{cm}^{2} / \mathrm{m}^{2}\right.$ body surface area)

Standardized internal orifice size (Z-value)

\section{Experience}

Years since 1977 when operation took place 

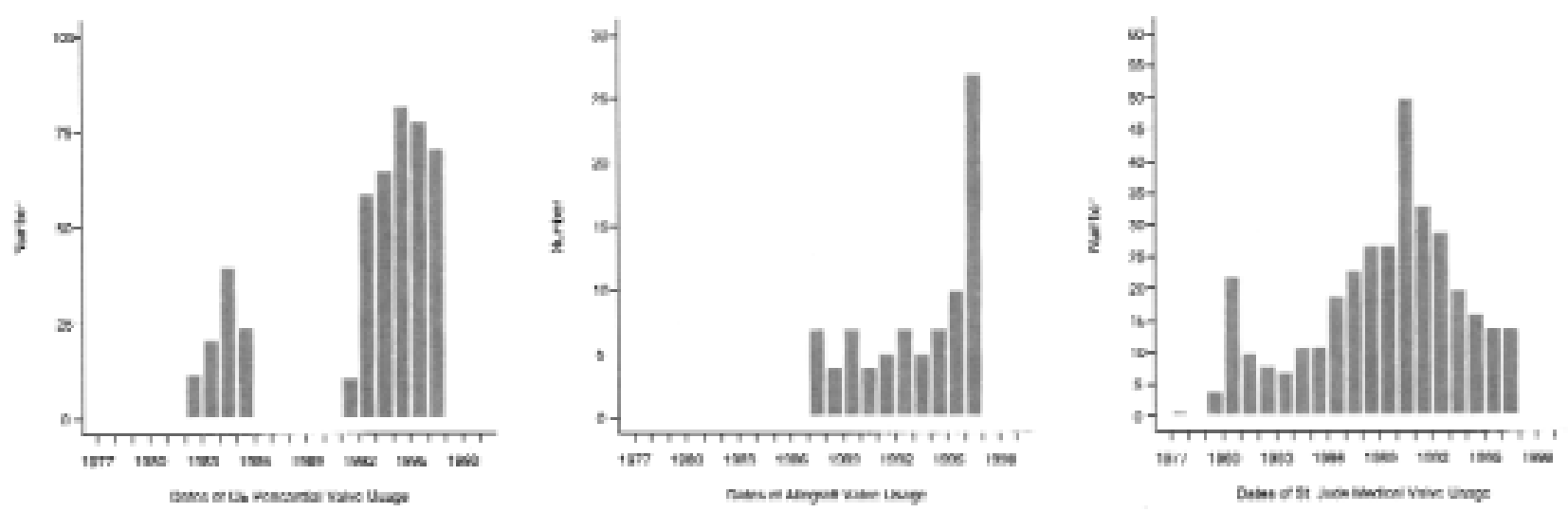

Appendix Fig 1. Valve usage across time.

\section{Propensity score}

Conditional probability of pericardial valve type (logit units) Conditional probability of mechanical valve type (logit units) Conditional probability of allograft valve type (logit units)

\section{Appendix II: The standardized valve size}

For a number of years, the quantitative expression of cardiac structures has been expressed in terms of the number of SDs a patient's structure deviates from normal. ${ }^{14,15}$ Generally, the normal structure size has been based on a logarithmic relation between structure size and body surface area. A standardized expression is particularly important in growing babies and children but has not been used extensively for adults. For this study, we used the following relation between aortic anulus diameter and body surface area (BSA), where ln is the natural logarithm:

$\ln [$ mean normal aortic anulus diameter $(\mathrm{mm})]=2.770403+$ $0.482279 \cdot \ln [\mathrm{BSA}]$

We used this, and its SD, to derive the $\mathrm{Z}$-value by using the following formula:

Z-value $=[\ln ($ internal orifice diameter $)-\ln ($ mean normal anulus diameter)]/0.09224

\section{Discussion}

Dr Friedrich W. Mohr (Leipzig, Germany). This is a very important study that contributes to and stimulates the discussion on patient prosthesis selection and mismatch in aortic valve surgery. Especially in patients with a small aortic anulus, sufficient postoperative effective orifice areas are required for optimal recovery. I think every one of us thought this was the primary goal. Your article is very much in contrast to the current knowledge that all of us have been trained to perform aortic valve surgery and to get the least gradient in surgery possible to overcome left ventricular hypertrophy.

For aortic valve replacement, the goal must be the achievement of optimal hemodynamics and regression of left ven- tricular hypertrophy. We thought it could be reached by using the largest possible prosthetic valves. In your study you could demonstrate that an effective prosthetic valve orifice area that is not less than 4 SDs from the native aortic anulus index is as efficient, and I think this is an important result. However, the literature demonstrates that especially in the early outcome operative mortality rate is higher in patients receiving very small aortic valves, and this is in contrast to your own experience.

Dr Medalion, I would like to ask you 3 questions. Do you think that, because this study was a nonrandomized trial and prosthesis selection was to the surgeon's taste, this statistical analysis is really able to finally answer this question? You are well aware of other reports with high, early operative mortality rates with very small prostheses. On the basis of your results, what do you think about stentless aortic valves for patients with small aortic roots? The risk factor of left ventricular hypertrophy and the measured mass of left ventricular hypertrophy did not seem to be analyzed in your study.

In randomized prospective trials of stented valves versus stentless valves, as well as in Tirone David's series and our series, it is clear that earlier and rapid regression of left ventricular hypertrophy occurs if you calculate this risk factor. Do you have any data on that?

Finally, please give us your current strategy from The Cleveland Clinic in patients with small aortic roots after you reviewed your data? Are you advising us not to hesitate to implant these small valves?

Dr Medalion. Thank you, Dr Mohr, for discussing the article. I will try to answer all 3 questions.

The findings of this study were somewhat surprising to us. We thought that there would be extremes of valve-patient mismatch in which we would see a negative effect on survival, and we used very extensive and advanced statistical analyses in attempts to define a level of mismatch that was important. However, we were unable to demonstrate this effect. There are, however, a couple of important points to keep in mind.

First, these operations were performed, in general, by surgeons with a bias in favor of larger valves, and therefore severe 
valve-patient mismatches were uncommon. Second, the end point of the study is survival. With this large number of patients being followed up, it is impossible to test exercise capacity and symptom status for them all. Valve size may be important for patients for whom a high activity level is important. In our current practice, we use aortic valve homografts, aortic rootenlarging procedures, and pulmonary valve autotransplantation for young patients with high activity level expectations. Thus we believe there are some indications for complex aortic root operations to achieve maximal valve efficiency.
However, the thought that no patient should ever receive a size 19 or size 21 valve because that strategy will lead to an increased risk of late death cannot be supported by these data. For most patients, the in-hospital risk of aortic valve replacement with standard prostheses is extremely low. Performing more complex operations makes sense only if they do not increase the risk of in-hospital mortality because the idea that a moderate valve-patient mismatch will lead to a shortened long-term survival is a concept that has no data to support it at the present time.

\section{ON THE MOVE?}

Send us your new address at least six weeks ahead

Don't miss a single issue of the journal! To ensure prompt service when you change your address, please photocopy and complete the form below.

Please send your change of address notification at least six weeks before your move to ensure continued service. We regret we cannot guarantee replacement of issues missed due to late notification.

\section{JOURNAL TITLE:}

Fill in the title of the journal here.

\section{OLD ADDRESS:}

Affix the address label from a recent issue of the journal here.

\section{NEW ADDRESS: \\ Clearly print your new address here.}

Name

Address

City/State/ZIP

\section{COPY AND MAIL THIS FORM TO:}

Periodical Subscription Services

Mosby, Inc.

11830 Westline Industrial Dr.

St. Louis, MO 63146-3318
OR FAX TO:

314-432-1158

N/ Mosby

\section{OR PHONE:}

1-800-453-4351

Outside the U.S., call

314-453-4351 